\title{
The Potential of Baobab (Adansonia digitata L.) Extracts as Biocontrol on the Growth and Aflatoxin Production by Aspergillus flavus and $A$. parasiticus
}

\author{
Saifeldin A. F. El-Nagerabi ${ }^{1}$, Abdulkadir E. Elshafie ${ }^{2}$, Suleiman S. AlKhanjari ${ }^{1}$, \\ Saif N. Al-Bahry ${ }^{2} \&$ Mohamed R. Elamin ${ }^{3}$ \\ ${ }^{1}$ Department of Biological Sciences and Chemistry, College of Arts and Sciences, University of Nizwa, Oman \\ ${ }^{2}$ Department of Biology, College of Science, Sultan Qaboos University, Oman \\ ${ }^{3}$ Department of Chemistry, Sudan Academy of Science, Khartoum North, Sudan \\ Correspondence: Saifeldin A. F. El-Nagerabi, Department of Biological Sciences and Chemistry, College of Arts \\ and Science, University of Nizwa, Birkat Al Mouz, Nizwa, P. O. Box 33, PC 616, Oman. Tel: 968-9636-5051. \\ E-mail: nagerabi@unizwa.edu.om; nagerabi@hotmail.com
}

\author{
Received: April 9, 2013 Accepted: May 12, 2013 Online Published: May 16, 2013 \\ doi:10.5539/jfr.v2n3p93 URL: http://dx.doi.org/10.5539/jfr.v2n3p93
}

\begin{abstract}
Moulds and associated mycotoxins, especially aflatoxins, are important factors that advesely affect food and feed produced from contaminated plant and animal prodcuts. They are lethal to humans and animals, which emphasizes the great concern in food and feed production. In this study, the effects of baobab (Adansonia digitata) extracts on the vegetative growth and aflatoxin secretion by A. flavus (SQU21) and A. parasiticus (CBS921.7) strains were exzmined. Different concentrations of baobab fruit extract $(1.5,3,5$, and $7 \% \mathrm{w} / \mathrm{v})$ and essential oil $(0.5,1,3$ and $5 \% \mathrm{v} / \mathrm{v})$ was used. Fruit extract of baobab apparently inhibited the total aflatoxin secretion up to $20.4-68.5 \%$ for $A$. flavus and $11.9-69.1 \%$ for $A$. parasiticus, whereas the inhibition of aflatoxin $\mathrm{B}_{1}$ production ranged between $29.9-79.2 \%$ and $13-68 \%$ for the two strains, respectively. The highest inhibition levels of total aflatoxin and aflatoxin $\mathrm{B}_{1}$ secretion by A. flavus $(47.2-95.7 \% ; 28.1-89.7 \%)$ and $A$. parasiticus $(42.7-93.3 \%$; 25.9-80.2\%) were obtained with essential oil extracted from baobab seeds. The two extracts significantly reduced the vegetative growth and the mycelial dry weights of selected fungi. This indicates the antifungal activity and inhibitory effect of baobab on the growth and aflatoxin production by the two toxigenic strains. Thus, fruit extract and essential oil of $A$. digitata can be suggested as potentially effective biocontrol and biopreservative substrates against food and feed contamination by aflatoxigenic moulds.
\end{abstract}

Keywords: Adansonia digitata, Aspergillus flavus, A. parasiticus, baobab fruit, essential oil

\section{Introduction}

Adansonia digitata L. (Baobab) of the family Malvaceae is a large iconic deciduous and stem-succulent tree indigenous to the dry regions of Africa. It is found in many countries of South Africa (Zimbabwe, Mozambique, South Africa), West Africa (Mali, Benin, Senegal, the Ivory Cost, Cameron, Burkino Faso), and East Africa Kenya, Uganda, Sudan, Tanzania) (Sidibé \& Williama, 2002; Wickens \& Lowe, 2008; Kamatou, VermaaK, \& Viljoen, 2011; Vermaak, Kamatou, Komane-Mofokeng, Viljoen, \& Beckett, 2011; De Smedt, Sanchez, Van den Bilcke, Simbo, Potters, \& Samson, 2012). In the past decade, different parts of the baobab tree have been reported to be useful and this has attracted the interest of pharmaceutical companies and scientists. This is due to its various traditional uses as medicinal, nutritional and cosmetic plant (Igboeli, Addy, \& Salami, 1997; Wickens \& Lowe, 2008; Buchmann, Prechsler, Hartl, \& Vogl, 2010; Kamatou et al., 2011). Recently, the European Commission authorized the importation of baobab fruit pulp as a novel food for human consumption (Buchamann et al., 2010). In 2009, it was approved by the Food and Drug Adminstration (FDA) as a food ingredient in the United States of America (Addy, 2009). The dry pulp is commonly used to prepare fruit juice with higher levels of vitamin $\mathrm{C}$ than orange, and calcium than milk (Assogbadjo, Chadare, Kakari, Fandohan, \& Baidu-Forson, 2012). Various plant parts such as leaves, bark, and fruit pulp have been traditionally used as immuno-stimulant, anti-inflammatory, analgesic, and pesticide, and in the treatment of fever, diarrhoea, cough, dysentery, haemoptysis, tuberculosis, microbial infection and worms (Wickens \& Lowe, 2008; Kamatou et al., 
2011; Vermaak et al., 2011). The seeds are used as roasted snacks, fermented and used as a thickening and flavouring agent in soup (Igboeli et al, 1997). The oil extracts are used as food, fuel, medicine, cosmetic applications and topical treatment of various conditions such as dandruff, muscle spasms, varicose veins and wounds (Chivandi, Davidson, \& Erlwanger, 2008; Kamatou et al., 2011; Vermak et al., 2011).

Mycotoxins are toxic secondary metabolites of fungal origin and natural contaminant of agricultural commodities under both pre- and post-harvest conditions (Wagacha \& Muthomi, 2008; Herzallah, 2009; Salim \& Ahmad, 2010). The species of the genus Aspergillus, Fusarium, and Penicillium are the major mycotoxin producing fungi. The most important mycotoxins are aflatoxins, fumonisins, and ochratoxins (Kumar, Basu, \& Rajendran, 2008). Aflatoxigenic fungi are the most devastating contaminants of different plants and animals products (Payne, 1998; Elshafie, Al Rashdi, Al-Bahry, \& Bakheit, 2002; Abdulkadir, Al-Ali, Al-Kildi, \& Jedah, 2004; Santacrose, Conversano, Casalino, Lai, Zizzadoro, \& Centoducati, 2008; El-Nagerabi, Al-Bahry, Elshafie, $\&$ AlHilali, 2012). Aflatoxins in general and aflatoxin $\mathrm{B}_{1}$ in particular are mutagenic and hepatocarcinogenic secondary metabolites secreted by Aspergillus flavus, A. parasiticus, A. nominus and A. pseudotamorii are pose serious effects on human and animal health (Sidhu, Chandra, \& Behl, 2009; Elshafie, ElMubarak, El-Nagerabi, \& Elshafie, 2010; Liu \& Wu, 2010; El-Nagerabi et al., 2012).

The vegetative growth and associated aflatoxin production by A. flavus and A. parasiticus were found to be affected by many extracts from different plant parts due to their fungicidal and fungistatic properties (Soliman \& Badeaa, 2002; El-Nagerabi et al., 2012). This includes dry leaves and calyx extracts of Hibiscus sabdariffa (Al-Shayeb \& Mabrook, 1984; El-Nagerabi et al., 2012), herbal compounds (Gowda, Malathi, \& Suganthi, 2004), and fruit rinds of Garcinia cowa and G. pendunculata (Joseph, Jayaprakasha, Seli, Jena, \& Sakariah, 2005). Leaf extract from Syzigium aromaticum, Cucuma longa, Allium sativum, and Ocimum sanctum showed significant antifungal activities and inhibit aflatoxin $\mathrm{B}_{1}$ production by $A$. flavus and $A$. parasiticus (Reddy, Reddy, \& Muralidharan, 2009). Similar effects were observed with essential oils from medicinal and herbal plants such as anise, caraway, cinnamon, black cinum, and fennel (Bullerman, Lieu, \& Seier, 1977; Farag, Daw, \& Abo-Raya, 1989; Soher, 1999; Patkar, Usha, Shetty, Poster, \& Lacey, 1993; Hasan, 1994; Montes-Belmont \& Carvajal, 1998; Soliman \& Badeaa, 2002). Oil of Nigella sativa at concentration of 1-3\% completely inhibited aflatoxin production (Maraqa, Alsharoa, Farah, Albjeirami, Shakya, \& Sallal, 2007; El-Nagerabi et al., 2012).

Many researchers worldwide are continuously assessing different detoxification methods and inhibition techniques on aflatoxin secretion by aflatoxigenic fungi (Gandomi, Misaghi, Basti, Bokaei, Khosravi, Abbasifar, \& Javan, 2009; Kumar, Shukla, Singh, \& Dubey, 2009; Oguz, 2011; El-Nagerabi et al., 2012). Reduction or inactivation of aflatoxin by various decontamination procedures using different physical and chemical methods have been studied extensively together with microbiologial degradation (Alberts, Gelderblom, Botha, \& Van Zyl, 2009; Kumar et al., 2009). Nevertheless, these synthetic chemicals are hazardous to humans and domestic animals as well as the environment (Szczerbanik, Jobling, Morris, \& Holford, 2007; Gandomi et al., 2009; Kumar et al., 2009; Prakash, Shukla, Sigh, Mishra, Dubey, \& Kharwar, 2011). This prompted us to search for simple, safe, and environment friendly antifungal and growth inhibitors from biological sources. Nonetheless, the antifungal, inhibitory, and detoxification effects of A. digitata extracts on the fungal growth and aflatoxin production had not been screened. Thus, there is high potential for extracts from $A$. digitata to inhibit the fungal growth and aflatoxin production by these aflatoxigenic fungi. The present investigations aim to evaluate the effects of fruit pulp powder and oil extracted from seeds of baobab on the fungal growth and aflatoxin secretion of two aflatoxigenic strains of A. flavus (SQU21) and A. parasiticus (CBS921.7). This will contribute with international efforts to fill the gap in our knowledge about the antimicrobial properties of baobab and possibly lead to developments in the food industry related to preparation, preservation, storage, and consumption.

\section{Materials and Methods}

\subsection{Fungal Isolates}

Two strains of high aflatoxin-producer fungi of Aspergillus flavus (SQU21) and A. parasiticus (CBS921.7) [NRR22999] were obtained from the culture collections of Sultan Qaboos University, Oman. These isolates were cultivated on Czapek Dox Agar (CDA) and described taxonomically using the manual prepared by Raper \& Fennel (1965). These strains were used as inoculum in this study.

\subsection{Source and Properties of Adansonia digitata Extracts}

The fruit powder of $A$. digitata pulp was purchased from AlNaser Company, Khartoum, Sudan. Numerous studies were carried on the nutritional constituents of baobab parts (Sidibé \& Williams, 2002; Chadare, Hounhouigan, Linnemann, Nout, \& Van Boekel, 2009; Assogbadjo et al., 2011). Biochemical analysis indicated that baobab parts (pulp, leaves and seeds) are rich in several microelements such as iron, vitamin C, A, E and F 
in addition to calcium, potassium, magnesium, zinc, proteins and lipids (Chadare et al., 2009). The oil extract of this plant was obtained from Chemistry for Life Company, Muscat, Oman. The chemical nature of the essential oil extracted from the seeds was reported by researchers. The oil is extremely stable with a half life of between 2 to 5 years, a high saponiofication value compared to other edible oils, and the iodine value is $87.9 \mathrm{~g} / 100 \mathrm{~g}$ as non-drying oil, with $33 \%$ saturated, $36 \%$ monosaturated and 31 polysaturated fatty acids in addition to palmitic and oleic acids as major constituents (Vermaak et al., 2011).

\subsection{Inoculation of Aspergillus Starins on Media Containing A. digitata Extracts}

A. flavus (SQU21) and A. parasiticus (CBS921.7) were inoculated onto Potato Dextrose Agar (PDA) and incubated at ambient temperature of $25 \pm 2{ }^{\circ} \mathrm{C}$ for 10 days. Sterile thin glass tubes of $5 \mathrm{~mm}$ in diameter were used to cut several discs from the growing cultures. Two discs of $5 \mathrm{~mm}$ in diameter were added aseptically to each flask containing $200 \mathrm{ml}$ sterile yeast malt broth with $1.5,3,5$, and $7 \mathrm{~g} / 100 \mathrm{ml}$ of Adansonia digitata fruit pulp extract and $0.5,1,3$ and $5 \mathrm{ml} / 100 \mathrm{ml}$ oil extract. As a control, fruit pulp extract and oil extract were mixed with yeast malt broth and without any fungal inoculation. Three inoculated flasks from each treatment were incubated at $25 \pm 2{ }^{\circ} \mathrm{C}$ for two weeks. Similarly inoculated flasks were used to determine the mycelial dry weight of the two fungal strains.

\subsection{Effect of A. digitata Fruit Extract and Oil on Pure Aflatoxin $B_{1}$}

Aflatoxin $B_{1}$ powder (Sigma Company) was added to $100 \mathrm{ml}$ sterile distilled water which gave an aflatoxin $\mathrm{B}_{1}$ concentration of $870 \mathrm{ppb}$. The highest concentrations from A. digitata fruit pulp $(7 \mathrm{~g} / 100 \mathrm{ml})$ and oil $(5 \mathrm{ml} / 100 \mathrm{ml})$ were chosen. For this, 7 grams of $A$. digitata fruit pulp and $5 \mathrm{ml}$ of oil were added to the different flasks of aflatoxin $\mathrm{B}_{1}$. The flasks were incubated at $25 \pm 2^{\circ} \mathrm{C}$ for 10 days. The aflatoxin concentration was measured.

\subsection{Extraction and Detection of Aflatoxin by Afla Test-P Affinity Column}

For aflatoxin extraction, similar method used in our previous study on the effect of Hibiscus sabdariffa extract and Nigella sativa oil on the growth and aflatoxin B1 of Aspergillus flavus and A. parasiticus strains was adopted (El-Nagerabi et al., 2012). For measuring the concentration of aflatoxin, calibrated Vicam fluorometer (Series-4EX) from Vicam Company, Milford, MA, USA was used. The fluorometer was set at excitation wavelength of $360 \mathrm{~nm}$ and emission wavelength of $440 \mathrm{~nm}$ (Elshafie \& Al-Shally, 1998).

\subsection{Statistics and Data Analysis}

To assess the variation between the effects of fruit and oil extracts of $A$. digitata extracts on the vegetative and aflatoxin production, one way ANOVA test (correlation coefficient) was used. The statistical package software SPSS (version 11.0) was used.

\section{Results and Discussion}

\subsection{Effects of Fruit Pulp Extract of Baobab on Fungal Growth and Aflatoxins Production}

The effects of various concentrations of Adansonia digitata (Baobab) fruit pulp extract on the total aflatoxin (Figure 1a), aflatoxin $\mathrm{B}_{1}$ (Figure 1b), and mycelia dry weight (Figure 1c) of A. flavus (SQU21) and A. parasiticus (CBS921.7) were recorded. The total aflatoxins and aflatoxin $\mathrm{B}_{1}$ production by the two Aspergillus strains were significantly $(p<0.05)$ reduced by the tested concentrations of baobab fruit extract $(1.5,3,5$, and $7 \mathrm{~g} / 100 \mathrm{ml})$ compared to the control. Similarly, the mycelial dry weight of the two fungal strains was significantly $(p<0.05)$ reduced by the different concentrations of baobab fruit pulp extract comparable to the control.

The antifungal activities and detoxification properties of different plant extracts were investigated by many researchers (Gandomi et al., 2009; Kumar et al., 2009; Oguz, 2011; El-Nagerabi et al., 2012). Nonetheless, based on the available literature, the antifungal ability and detoxification properties of fruit extract of $A$. digitata on the fungal growth and aflatoxins production by Aspergillus species had not been evaluated before. To our knowledge, this is the first study on the biological activities of different extracts from this plant. However, extracts from fruit rind of Garcinia cowa and G. penduculata completetely inhibited the growth and aflatoxin $\mathrm{B}_{1}$ production by $A$. flavus (Joseph et al., 2005). Threrefore, it is possible that fruit and other extracts from $A$. digitata could reveal similar inhibitory effects on the fungal growth and aflatoxins secretion by the two aflatoxigenic strain of $A$. flavus and A. parasiticus. Hence, it is evidently important to evaluate the inhibitory effect of various extracts from $A$. digitata against the fungal growth and aflatoxin production by aflatoxigenic fungi and compared with the similar studies which used different extracts from herbal and medicinal plants. In the present investigations, the concentrations of baobab fruit extract (1.5-7\%) apparently inhibited total aflatoxin production by $20.4-68.5 \%$ for A. flavus (SQU21) and 11.9-69.1\% for A. parasiticus (CBS921.7), whereas the inhibition of aflatoxin $\mathrm{B}_{1}$ production ranged between $29.9-79.2 \%$ and $13-68 \%$ for the two strains as suggested by Joseph et al. (2005) 
using similar extract from fruit rind of G.cowa and G. penduculata. Also neem seed cake and leaf extract of Azadirchta indica inhibited the fungal growth and aflatoxin production by A. flavus and A. parasiticus. Other studies showed similar inhibition of the fungal growth and aflatoxin production. For example, aqueous extracts from mature leaves of Vernonia amygdalina, Sena elata and Cymbopogon citrulus (Suleiman, Emua, \& Taiga, 2008), plant extract of Syzigium aromaticum, Curcuma longa, Allium sativum and Ocimum sanctum (Reddy et al., 2009), herbal compounds (Gowda et al., 2004), and dry leaves and calyx extracts of Hibiscus sabdariffa (A-Shayeb \& Mabrook, 1984; El-Nagerabi et al., 2012). Cinnamon extract concentrations of $0.02-20 \%$ inhibit aflatoxin production by $25-100 \%$, and $2 \%$ of cinnamon led to $97 \%$ inhibition of aflatoxin secretion by aflatoxigenic fungi (Bullerman et al., 1977). About 91.5-97.9\% reduction in aflatoxin $\mathrm{B}_{1}$ production by $A$. flavus and A. parasiticus was caused by leaf and calyx extracts (5-12.5\%) of H. sabdariffa (El-Nagerabi et al., 2012; Al-Shayeb \& Mabrook, 1984). Our results showed that the highest inhibition levels of total aflatoxin (68.5-69.1\%) and aflatoxin $\mathrm{B}_{1}(68-79.1 \%)$ were reported at $7 \%$ concentration of baobab fruit extract. Therefore, it is possible that various growth inhibitors present in this plant extracts would affect aflatoxin secretion by aflatoxigenic fungi. On the other hand, inoculation of A. flavus (SQU21) and A. parasiticus (CBS921.7) strains on yeast malt broth containing different concentrations of baobab fruit extract $(1.5,3,5$, and $7 \mathrm{~g} / 100 \mathrm{ml})$ significantly inhibited the fungal growth and mycelial dry weights of the two strains. Similarly, extract from the dried leaves of H. sabdariffa evidently retarded the growth and vigour of different fungi (Guerin \& Revillere, 1984). On the contrary, calyx extract (5-12.5\%) from H. sabdariffa did not show any effect on the mycelial growth of Aspergillus species (El-Nagerabi et al., 2012). Some herbal drugs and medicinal plants inhibit the mycelial growth of $A$. flavus and A. parasiticus while others improved mycelial growth, but retarded aflatoxin secretion (Bahk \& Marth, 1983; Gowda et al., 2004; Joseph et al., 2005; Suleiman et al., 2008; Reddy et al., 2009; Da Costa et al., 2010). Cinnamon at the concentrations of between $0.02-2.0 \%$ inhibited aflatoxin biosynthesis and the growth of $A$. parasiticus by 16-100\% (Bullerman et al., 1977). The leaf extracts cassia and bay enhance the mycelial growth of A. parasiticus and inhibit the mycelial growth and aflatoxin production by A. flavus (Paranagama, Abeysekera, Abeywickrama, \& Nugaliyadde, 2003; Krishnamsrthy, \& Shashikala, 2006; Sandosskumar, Karthikeya, Mathiyazhaga, Mohankumar, Chandrasekar, \& Velazhahan, 2007). Therefore, it is evident that $A$. digitata fruit extract showed antifungal activities and inhibitory effect on aflatoxin production by A. flavus and A. parasiticus.

\subsection{Effects of Essential Oil of Baobab on Fungal Growth and Aflatoxins Production}

The uses of essential oils (EOs) extracted from herbal, medicinal and aromatic plants against the fungal growth and aflatoxin production of A. flavus and A. parasiticus have been suggested by many researchers (Maraqa et al., 2007; El-Nagerabi et al., 2012). They had different fungistatic activities (Gandomi et al., 2009; Shukla et al., 2012). Nigella sativa oil at $3 \%$ completely inhibited (Maraqa et al., 2007). At concentrations of 1-3\%, this oil caused 47.9-58.3\% reduction in aflatoxin $\mathrm{B}_{1}$ for $A$. flavus and $32-48 \%$ for $A$. parasiticus strains (El-Nagerabi et al., 2012). Oil of cassia and bay leaves reduced aflatoxin $\mathrm{B}_{1}(98 \%)$ and stimulated fungal growth, whereas coriander oil had no effect on the fungal growth and its toxigenicity (Attanda, Akqan, \& Oluwafemi, 2007). Aflatoxin $B_{1}$ production by NKD-208 isolates of $A$. flavus was strongly inhibited at lower fungistatic concentrations of essential oil of Callistemon lanceolatus (Shukla et al., 2012). All concentrations of Zataria multifora essential oil exhibited significant inhibition of fungal growth as well as spore production (Gandomi et al., 2009). Ocimum gratissimum oil shows better efficacy as a fungitoxicant than prevailing fungicide Wettasul-80 (Prakash et al., 2011). The essential oils of $T$. eriocalyx and T. x-porlock were evidently fungicidal and inhibitory to aflatoxin production (Rasooli \& Abyaneh, 2004). Of the 96 plant extracts, EOs proved to be the most effective extract controlling aflatoxigenic strains (Bluma, Amaiden, \& Etcheverry, 2008). Frankincense of B. carteri at $2 \%$ (v/v) showed the strongest mycelium inhibition against $A$. flavus and other pathogenic fungi (Udomsilp et al., 2009). In this investigation, the effects of different concentrations of $A$. digitata essential oil $(0.5,1,3$, and $5 \mathrm{ml} / 100 \mathrm{ml})$ on total aflatoxin secretion (Figure 2a), aflatoxin $\mathrm{B}_{1}$ (Figure 2b) and the mycelial growth (Figure 2c) of A. flavus (SQU21) and $A$. parasiticus (CBS921.7) were reported. The results showed that the oil of baobab significantly $(p<0.05)$ inhibited total aflatoxin secretions up to $47.2-95.7 \%$ for $A$. flavus and $42.7-93.3 \%$ for $A$. parasiticus, whereas aflatoxin $\mathrm{B}_{1}$ showed inhibition of $28.1-89.7 \%$ and $25.9-80.2 \%$, respectively. The mycelial dry weights of the Aspergillus strains were significantly $(p<0.05)$ reduced by the tested concentrations of $A$. digitata oil. This indicates the antifungal and inhibitory effects of baobab essential oil against the growth and aflatoxin production by the two strains of $A$. flavus (SQU21) and A. parasiticus (CBS921.7). Similar findings were reached by many authors using different oils from Nigella sativa (El-Nagerabi et al., 2012), cassia and bay (Attanda et al., 2007), Cymbopogon flexuous (Kumar et al., 2009), Callistemon laceolatus (Shukla et al., 2012), Zataria multifora (Gandomi et al., 2009), and Ocimum gratissimum (Prakash et al., 2011). 


\subsection{Detoxification of Aflatoxins $B_{1}$ by Fruit Extract and Essential Oil of Baobab}

Detoxifications with biological factors offer promising alternatives for aflatoxin elimination and maintaining the quality and safety of food and feed (Alberts et al., 2009; Oguz, 2011; Prakash et al., 2011). The ability of some herbal and medicinal plants as detoxifying agents was suggested by many researchers (Sandosskumar et al., 2007; El-Nagerabi et al., 2012). This includes Garlic (Allium sativum L. x) and onion (Allium cepa L.) roots extracts which cause $58.5 \%$ reduction in aflatoxin $\mathrm{B}_{1}$. Seed extract of Trachyspermum ammi degraded $90 \%$ of aflatoxin $\mathrm{G}_{1}$ by altering the ring structure of lactone (Velazhahan, Vijayanandraj, Vijayasamundeeswari, Parandidharan, Samiyappan, Iwamoto, Friebe, \& Muthukrishnan, 2010). The presence of inactivation factors in T. ammi seed extract was responsible from $80 \%$ reduction of total aflatoxin content (Hajare, Haijare, \& Sharma, 2006). In the present evaluation, the strains of the two selected Aspergillus species are aflatoxin-producers and secreting different level of aflatoxins. In the present study, we investigated the effect of the the highest concentrations of fruit pulp $(7 \% \mathrm{w} / \mathrm{v})$ and oil extract $(5 \% \mathrm{v} / \mathrm{v})$ of $A$. digitata on $780 \mathrm{ppb}$ aflatoxin $\mathrm{B}_{1}$ incubated at $25-29^{\circ} \mathrm{C}$ for 10 days. The results showed that the two extracts ( $7 \%$ fruit pulp $774 \mathrm{ppb} ; 5 \%$ oil $776 \mathrm{ppb}$ ) have no detoxification effect on pure aflatoxin $\mathrm{B}_{1}$ comparison with the control $(780 \mathrm{ppb})$. This suggests the non-detoxification properties of these extracts on aflatoxin $\mathrm{B}_{1}$. Therefore, it is apparent that fruit and oil extracts of $A$. digitata had antifungal and inhibitory effect on aflatoxin secretion by Aspergillus strains (A. flavus SQU21 and A. parasiticus CBS921.7).

\section{Conclusion}

This paper describes the effects of fruit pulp extract and essential oil from the seeds of A. digitata (Baobab) on the growth and inhibition of aflatoxin production of A. flavus (SQU21) and A. parasiticus (CBS921.7). As far as we know, this is the first report on the biological activities of baobab on the fungal growth and aflatoxin secretion by aflatoxigenic fungi. The overall results demonstrate that both fruit extract and essential oil of this plant inhibited the mycelial dry weights and aflatoxins production by the two strains of Asppergillus species. The two extracts did not detoxify pure aflatoxin $\mathrm{B}_{1}$. This indicates the antifungal activities and inhibitory effect of $A$. digitata extracts against moulds contamination. Therefore, baobab fruit and its essential oil can be suggested as plant additives and biopreservatives which enhance the nutritive value, quality, and protection against aflatoxin contamionation as well as storage life. More phytochemical analysis is needed to identify the active chemical ingredients and testing their antimicrobial activites against different microorganisms and mycotoxins invasion. This will bring to the literature useful information which eveually promotes the quality of food and feed products and related agricultural and pharmaceutical industries.

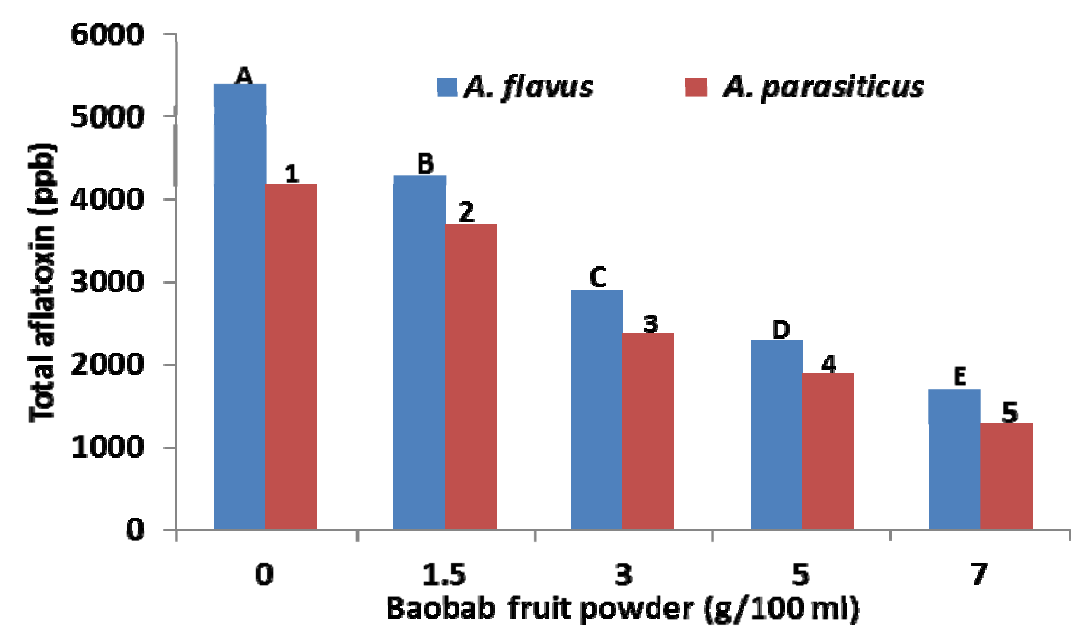

Figure 1a. Total aflatoxin production of $A$. flavus strain SQU21 and A. parasiticus strain CBS921.7 at different concentrations of $A$. digitata fruit extract (Identical numbers and letters indicate no significant diffrence, $p<$ $0.05)$ 


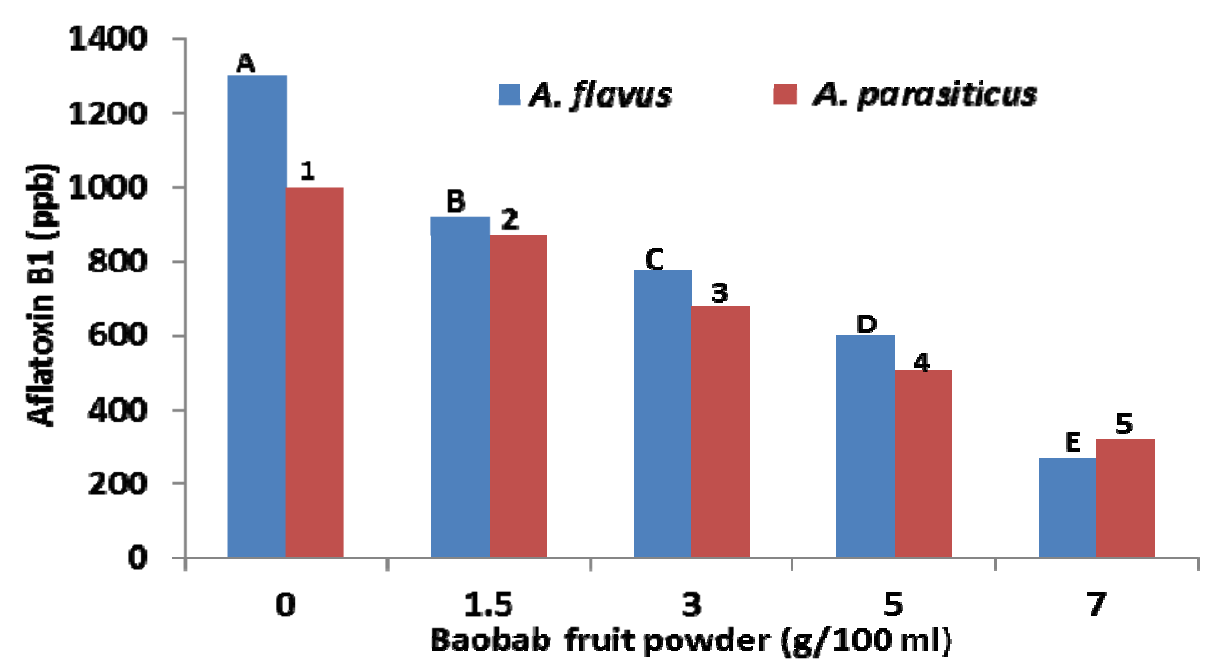

Figure 1b. Aflatoxin $\mathrm{B}_{1}$ production of $A$. flavus strain SQU21 and A. parasiticus strain CBS921.7 at different concentrations of $A$. digitata fruit extract (Identical numbers and letters indicate no significant diffrence, $p<$ $0.05)$

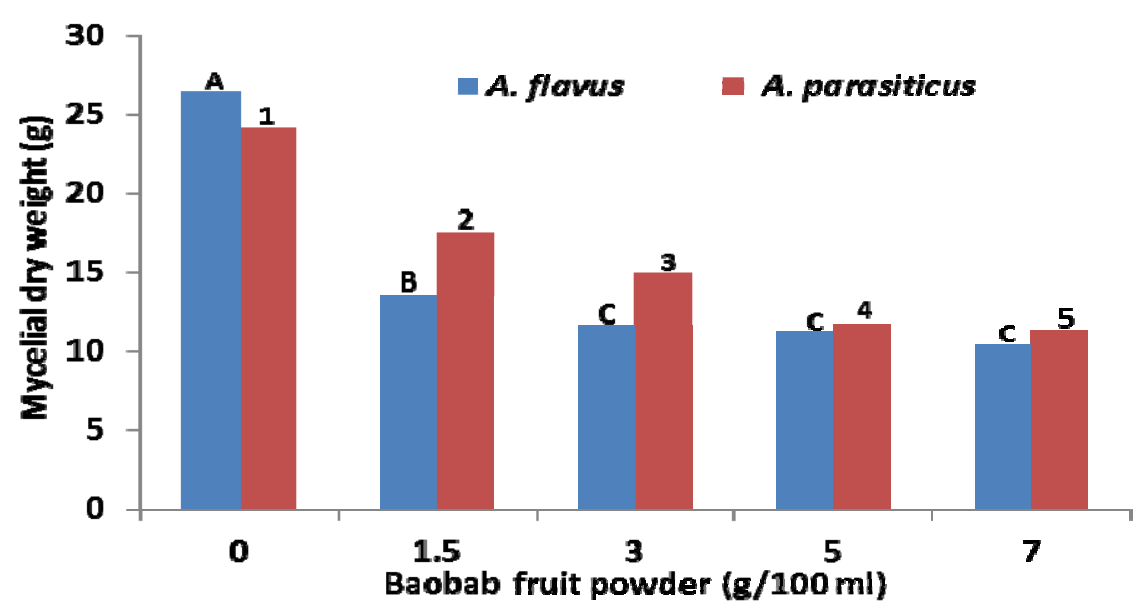

Figure 1c. Mycelial dry weight of A. flavus strain SQU21 and A. parasiticus strain CBS921.7 at different concentrations of $A$. digitata fruit extract (Identical numbers and letters indicate no significant diffrence, $p<$ $0.05)$

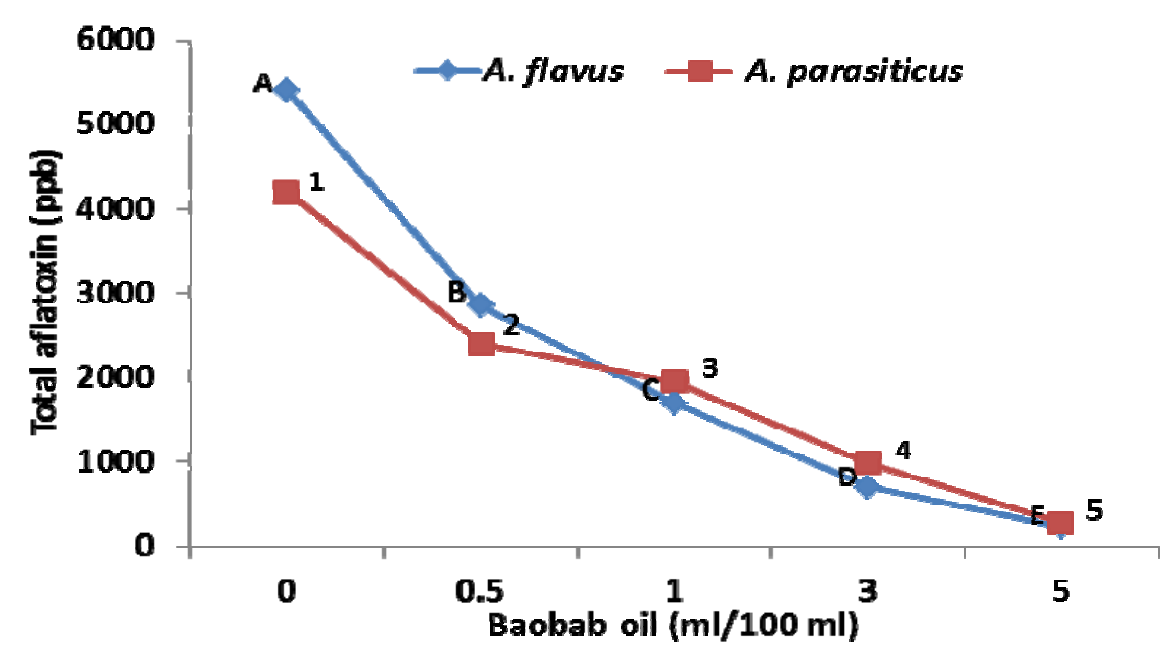

Figure 2a. Total aflatoxin production of $A$. flavus strain SQU21 and A. parasiticus strain CBS921.7 at different concentrations of $A$. digitata oil extract (Identical numbers and letters indicate no significant diffrence, $p<0.05$ ) 


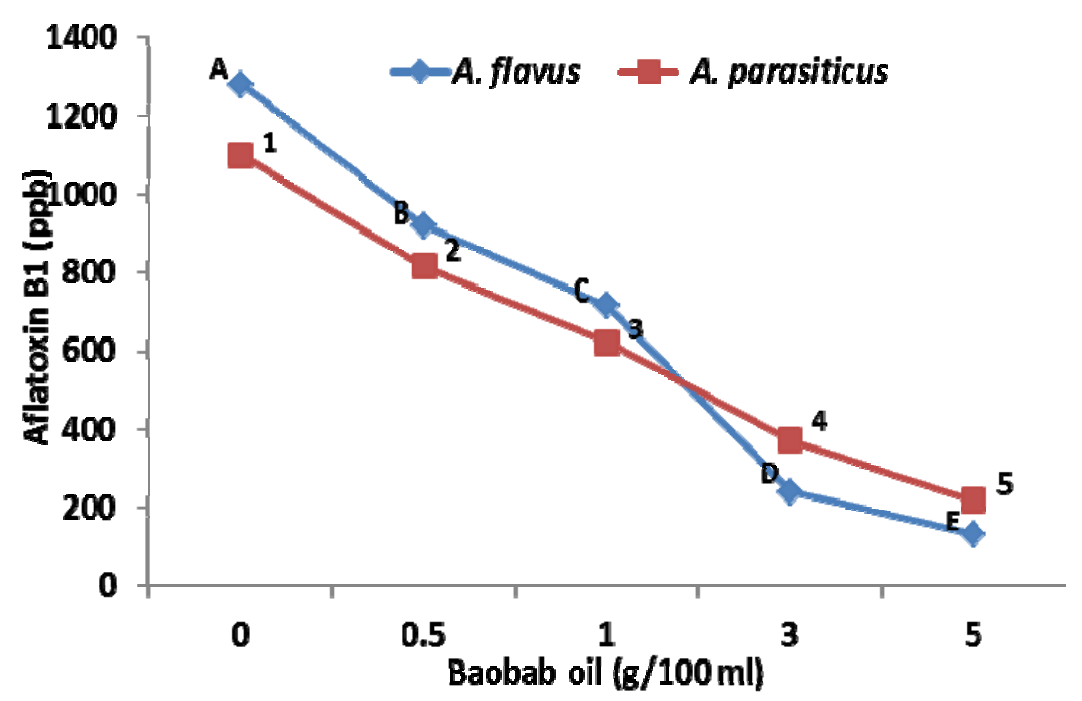

Figure 2b. Aflatoxin $\mathrm{B}_{1}$ production of A. flavus strain SQU21 and A. parasiticus strain CBS921.7 at different concentrations of $A$. digitata oil extract (Identical numbers and letters indicate no significant diffrence, $p<0.05$ )

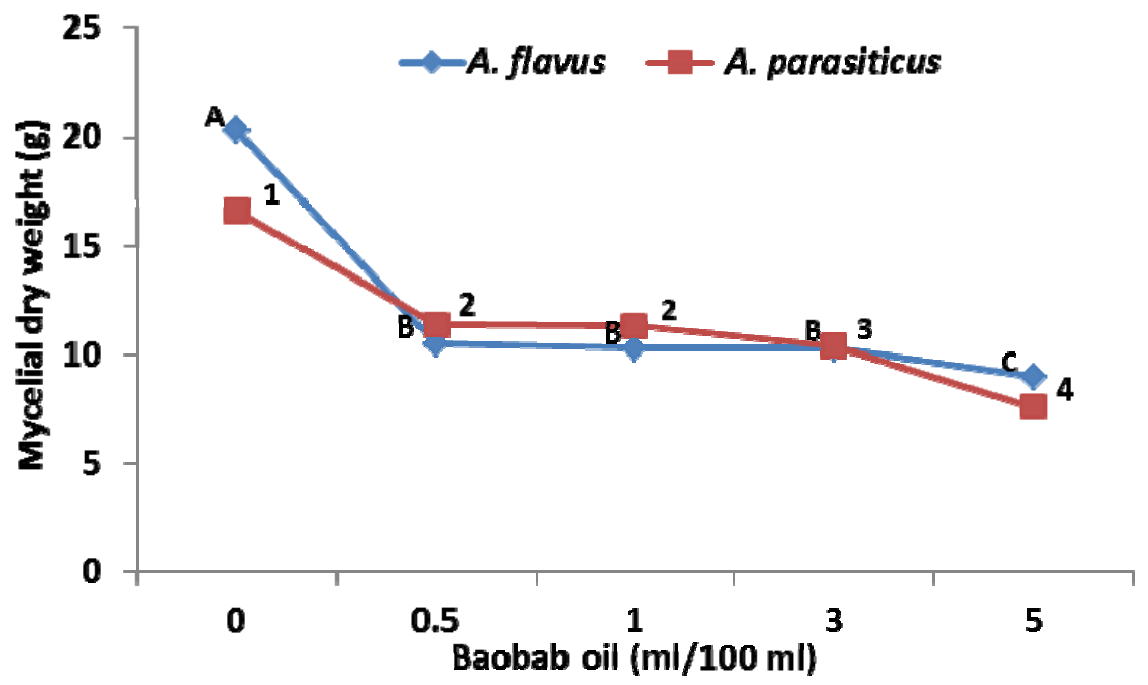

Figure 2c. Mycelial dry weight of A. flavus strain SQU21 and A. parasiticus strain CBS921.7 at different concentrations of $A$. digitata oil extract (Identical numbers and letters indicate no significant diffrence, $p<0.05$ )

\section{Acknowledgements}

This research was supported by University of Nizwa. We thank the Department Department of Biology, College of Science, Sultan Qaboos University for facilities. We thank the Writing Center of University of Nizwa for editing the English language of this paper.

\section{References}

Abdulkadar, A. H. W., Al-Ali, A. A., Al-Kildi, A. M., \& Al-Jedah, J. H. (2004). Mycotoxins in food products available in Qatar. Food Control, 15, 543-548. http://dx.doi.org/10.1016/j.foodcont.2003.08.008

Addy, R. (2009). Baobab Fruit Approved as Food Ingredient in US. Retrieved from http://www.nutraingredients-usa.com/content/view/print/2595742009

Alberts, J. F., Gelderblom, W. C. A., Botha, A., \& Van Zyl, W. H. (2009). Degradation of aflatoxin B by fungal laccaze enzymes. International Journal of Food Microbiology, 135, 47-52. http://dx.doi.org/10.1016/j.ijfoodmicro.2009.07.022 
Al-Shayeb, N. M., \& Mabrook, S. S. (1984). Utilization of some edible and medical plants to inhibit aflatoxin formation. Nutrition Report International, 29, 273-282.

Assogbadjo, A. E., Chadare, F. J., Kakaï, R. G., Fandohan, B., \& Baidu-Forson, J. J. (2012). Variation in biochemical composition of baobab (Adansonia digitata) pulp, leaves and seeds in relation to soil types and tree provenances. Agriculture, Ecosystems and Environment, 157, 94-99. http://dx.doi.org/10.1016/j.agee.2012.01.021

Bahk, J., \& Marth, E. H. (1983). Aflatoxin production is inhibited by selected herbal drugs. Mycopathologia, 83, 129-134. http://dx.doi.org/10.1007/BF00437018

Buchmann, C., Prehsler, S., Hartl, A., \& Vogl, C. R. (2010). The importance of baobab (Adansonia digitata L.) in rural West African subsistence-Suggestion of a cautionary approach to international market export of baobab fruits. Ecol. Food Nutr., 49, 145-172. http://dx.doi.org/10.1080/03670241003766014

Bullerman, L. B., Lieu, F. Y., \& Seier, A. S. (1977). Inhibition of growth and aflatoxin production by cinnamon and clove oils, cinamic aldehyde and eugenol. Journal of Food Science, 42, 1107-1108. http://dx.doi.org/10.1111/j.1365-2621.1977.tb12677.x

Bulma, R., Amaiden, M. R., \& Etcheverry, M. (2008). Screening of argentine plant extracts: impact on growth parameters and aflatoxin B1 by Aspergillus section Flavi. International Journal of Food Microbiology, 122, 114-125. http://dx.doi.org/10.1016/j.ijfoodmicro.2007.11.050

Chadare, F. J., Hounhouigan, J. D., Linneman, A. R., Nout, M. J. R., \& Van Boekel, A. M. J. S. (2008). Indigenous knowledge and processing of Adansonia digitata L. food products in Benin. Ecol. Food Nutrition, 47, 338-362. http://dx.doi.org/10.1080/03670240802003850

Chadare, F. J., Hounhouigan, J. D., Linneman, A. R., Nout, M. J. R., \& Van Boekel, A. M. J. S. (2009). Baobab food products: a review of their composition and nutritional value. Critical Review of Food Science, 49, 254-274. http://dx.doi.org/10.1080/10408390701856330

Chivandi, E., Davidson, B. C., \& Erlwanger, K. H. (2008). A comparison of the lipid and fatty profiles from the kernels of the fruit (nuts) of Ximenia caffra and Ricinodendron rautanenii from Zimbabwe. Industrial Crops and Products, 27, 29-32. http://dx.doi.org/10.1016/j.indcrop.2007.06.002

Da Costa, C. L., Geraldo, M. R. F., Arrotéia, C. C., \& Kemmelmeier, C. (2010). In vitro activity of neem oil [Azadirachta indica A. Juss (Meliaceae)] on Aspergillus flavus growth, sporulation, viability of spores, morphology and aflatoxins B1 and $\mathrm{B}_{2}$ production. Advances in Bioscience and Biotechnology, 1, 292-299. http://dx.doi.org/10.4236/abb.2010.14038

De Smedt, S. Sanchez, A. C., Van den Bilcke, N., Simbo, D., Potters, G., \& Samson, R. (2012). Functional responses of baobab (Adansonia digitata 1.) seedlings to drought conditions: Differences between western and south-eastern Africa. Environmental and Experimental Botany, 75, 181-187. http://dx.doi.org/10.1016/j.envexpbot.2011.09.011

El-Nagerabi, S. A. F., Al-Bahry, S. N., Elshafie, A. E., \& AlHilali, S. (2012). Effect of Hibiscus sabdariffa extract and Nigella sativa oil on the growth and aflatoxin $\mathrm{B}_{1}$ production of Aspergillus flavus and Aspergillus parasiticus strains. Food Control, 25, 59-63. http://dx.doi.org/10.1016/j.foodcont.2011.09.033

Elshafie, A. E., \& Al-Shally, N. S. (1998). Mycoflora and mycotoxigenic moulds of pistachio nuts for human consumption in the Sultanate of Oman. Science Technology, 3, 1-6.

Elshafie, A. E., Al Rashdi, T. A., Al Bahry, S. N., \& Bakheit, C. (2002). Fungi and aflatoxins associated with spices in the Sultanate of Oman. Mycopathologia, 155, 155-160. http://dx.doi.org/10.1023/A:1020427527963

Elshafie, S. Z. B., El Mubarak, A., El Nagerabi, S. A. F., \& Elshafie, A. E. (2010). Aflatoxin B contamination of traditionally processed peanut butter for human consumption in Sudan. Mycopathologia, 171(6), 435-439. http://dx.doi.org/10.1007/s11046-010-9378-2

Farag, R., Daw, Z., \& Abo-Raya, S. (1989). Influence of some spice essential oil on A. parasiticus growth and production of aflatoxins in a synthetic medium. Journal of Food Science, 54(1), 74-76. http://dx.doi.org/10.1111/j.1365-2621.1989.tb08571.x

Gandomi, H., Misaghi, A., Basti, A. A., Bokaei, S., Khosravi, A., Abbasifar, A., \& Javan, A. J. (2009). Effect of Zataria multifora Bioss. Essential oil on growth and aflatoxin formation by Aspergillus flavus in culture 
media and cheese. Food and Chemical Toxicology, 47, 2397-2400. http://dx.doi.org/10.1016/j.fct.2009.05.024

Gowda, N. K. S., Malathi, V., \& Suganthi, R. U. (2004). Effect of some chemical and herbal compounds on growth of Aspergillus parasiticus and aflatoxin production. Animal Feed Science and Technology, 116, 281-291. http://dx.doi.org/10.1016/j.anifeedsci.2004.02.008

Hajare, S. S., Haijare, S. H., \& Sharma, A. (2006). Aflatoxin inactivation suing aqueous extract of Ajowan (Trachyspermum ammi) seeds. Journal of Food Science, 70, 29-34. http://dx.doi.org/10.1111/j.1365-2621.2005.tb09016.x

Hasan, H. A. H. (1994). Inhibition of mycoflora and zearalenone on rice by selected essential oils. Pakistan Journal of Scientific and Industrial Research, 37(11), 471-473.

Herzallah, S. M. (2009). Determination of aflatoxins in eggs, milk, meat and meat products using HPLC fluorescent and UV detectors. Food Chemistry, 114, 1141-1146. http://dx.doi.org/10.1016/j.foodchem.2008.10.077

Igboeli, L. C., Addy, E. O. H., \& Salami, 1. I. (1997). Effects of some processing techniques on the antinutrient contents of baobab seeds (Adansonia digitata). Bioresource Technology, 59, 29-31. http://dx.doi.org/10.1016/S0960-8524(96)00132-0

Joseph, G. S., Jayaprakasha, G. K., Selvi, A. T., Sena, B. S., \& Sakariah, K. K. (2005). Antiaflatoxigenic and antioxidant activities of Garcinia extract. International Journal of Food Microbiology, 101, 153-160. http://dx.doi.org/10.1016/j.ijfoodmicro.2004.11.001

Kamatou, G. P. P., Vermaak, I., \& Viljoen, A. M. (2011). An updated review of Adansonia digitata: A commercially important African tree. South African Journal of Botany, 77, 908-919. http://dx.doi.org/10.1016/j.sajb.2011.08.010

Krishnamsrthy, Y. L., \& Shashikala, J. (2006). Inhibition of aflatoxin B production of Aspegillus flavus, isolated from soybean seeds by certain natural plant products. Letters in Applied Microbiology, 43, 469-474. http://dx.doi.org/10.1111/j.1472-765X.2006.02011.x

Kumar, A., Shukla, R., Singh, P., \& Dubey, N. K. (2009). Biodeterioration of some herbal raw materials by storage fungi and aflatoxin and assessment of Cymbopogon flexuous essential oil and its components as antifungal. $\begin{array}{llll}\text { International Biodeterioration and } & \text { 712-726. }\end{array}$ http://dx.doi.org/10.1016/j.ibiod.2009.03.011

Kumar, V., Basu, M. S., \& Rajendran, T. P. (2008). Mycotoxin research and mycoflora in some commercially $\begin{array}{lllll}\text { important agricultural commodities. Crop Protection, } & \text { 27, }\end{array}$ http://dx.doi.org/10.1016/j.cropro.2007.12.011

Liu, Y., \& Wu, F. (2010). Global burden of aflatoxin-induced hepatocellular carcinoma: A risk assessment. Environmental Health Prespectives, 118, 818-824. http://dx.doi.org/10.1289/ehp.0901388

Maraqa, A., Alsharoa, N. F., Farah, H., Albjeirami, W. M., Shakya, A. K., \& Sallal, A. J. (2007). Effect of Nigella sativa extract and oil on aflatoxin production by Aspergillus flavus. Turkish Journal of Biology, 31, 155-159.

Mishra, A. K., \& Dubey, N. K. (1994). Evaluation of some essential oils for their toxicity against fungi causing deterioration of stored food commodities. Applied and Environmental Microbiology, 60(4), 1101-1105.

Montes-Belmont, R., \& Carvajal, M. (1998). Control of Aspergillus flavus in maize with plant essential oils and their components. Journal of Food Protection, 61(5), 616-619.

Oguz, H. (2011). A review from experimental trials on detoxification of aflatoxin in poultry feed. Eurasian Journal of Veterinary Sciences, 27, 1-12.

Oussalah, M., Caillet, S., Saucier, L., \& Lacroix, M. (2007). Inhibitory effect of selected plant essential oils on growth of four pathogenic bacteria: E. coli O157:H7, Salmonella typhimurium, Staphylococcus aureus and Listeria monocytogenes. Food Control, 18, 414-420. http://dx.doi.org/10.1016/j.foodcont.2005.11.009

Paranagama, P. A., Abeysekera, K. H. T., Abeywickrama, K. P., \& Nugaliyadde, L. (2003). Fungicidal and anti-aflatoxigenic effects of the essential oil of Cymbopogon citrates (DC) Straps. (Lemongrass) against Aspergillus flavus link isolated from stored rice. Letters in Applied Microbiology, 37, 86-90. http://dx.doi.org/10.1046/j.1472-765X.2003.01351.x 
Patkar, K., Usha, C., Shetty, H., Poster, N., \& Lacey, J. (1993). Effect of spice essential oils on growth and aflatoxin B1 production by A. flavus. Letter in Applied Microbiology, 17(2), 49-51. http://dx.doi.org/10.1111/j.1472-765X.1993.tb00367.x

Payne, G. A. (1998). Process of contamination by aflatoxin-producing fungi and their impacts on crops. In K. K. Sinha \& D. Bhatnagar (Eds.), Mycotoxins in agriculture and food safety (pp. 279-306). New York: Marcel Dekker.

Prakash, B., shukla, R., Singh, P., Mishra, P. K., Dubey, N. K., \& Kharwar, R. N. (2011). Efficacy of chemically characterized Ocimum gratissimum L. essential oil as an antioxidant and a safe plant based antimicrobial against fungal and aflatoxin $\mathrm{B}_{1}$ contamination of spices. Food Research International, 44, 385-390. http://dx.doi.org/10.1016/j.foodres.2010.10.002

Prakash, B., Singh, P., Kedia, A., \& Dubey, N. K. (2012). Assessment of some essential oil as food preservatives based on antifungal, antiaflatoxin, antioxidant activities and in vitro efficacy in food system. Food Research International, 49, 201-208. http://dx.doi.org/10.1016/j.foodres.2012.08.020

Raper, K. B., \& Fennell, D. I. (1965). The genus Aspergillus (pp. 686). Baltimore: The Williams and Wilkins Company.

Rasooli, I., \& Abyaneh, M. R. (2004). Inhibitory effects of Thyme oils on growth and aflatoxin production by Aspergillus parasiticus. Food Control, 15, 479-483. http://dx.doi.org/10.1016/j.foodcont.2003.07.002

Reddy, K. R. N., Reddy, C. S., \& Muralidharan, K. (2009). Potential of botanicals and biocontrol agents on growth and aflatoxin production by Aspergillus flavus infecting rice grains. Food Control, 20, 173-178. http://dx.doi.org/10.1016/j.foodcont.2008.03.009

Salim, N. M., \& Ahmad, R. (2010). Mycotoxins in food from Jordan: preliminary survey. Food Control, 21, 1099-1103. http://dx.doi.org/10.1016/j.foodcont.2010.01.002

Santacrose, M. P., Conversano, M. C., Casalino, E., Lai, O., Zizzadoro, C., Centoducati, G., \& Crescenzo, G. (2008). Aflatoxins in aquatic species: metabolism, toxicity and perspectives. Reviews in Fish Biology and Fisheries, 18, 99-130. http://dx.doi.org/10.1007/s11160-007-9064-8

Shukla, R., Singh, P., Prakash, B., \& Dubey, N. K. (2012). Antifungal, aflatoxin inhibition and antioxidant activity of Callistemon lanceolatus (Sm.) sweet essential oil and its major component 1,8-cineole angainst fungal isolates from chickpea. Food Control, 25, 27-33. http://dx.doi.org/10.1016/j.foodcont.2011.10.010

Sidhu, O. P., Chandra, H., \& Behl, H. M. (2009). Occurrence of aflatoxins in mahua (Madhuca indica Gmel.) seeds: Synergistic effect of plant extracts on inhibition of Aspergillus flavus growth and aflatoxin production. Food and Chemical Toxicology, 47, 774-777. http://dx.doi.org/10.1016/j.fct.2009.01.001

Sidibé, M., \& Williams, J. T. (2002). Baobab. Adansonia digitata L. International Centre for Underutilised Crops, Southampton.

Soher, E. A. (1999). Prevention of the growth and aflatoxin production of Aspergillus flavus by some spice essential oils. Minufiya Journal of Agriculture Research, 24(2), 563-576.

Soliman, K. M., \& Badeaa, R. I. (2002). Effect of oil extracted from some medicinal plants on different mycotoxigenic fungi. Food and Chemical Toxicology, 40, 1669-1675. http://dx.doi.org/10.1016/S0278-6915(02)00120-5

Suleiman, M. N., Emua, S. A., \& Taiga, A. (2008). Effect of aqueous extracts on a spot fungus (Fusarium sp.) isolated from cowpea. American-Eurasian Journal of Sustainable Agriculture, 2, 261-263.

Szczerbanik, M., Jobling, J., Morris, S., \& Holford, P. (2007). Essential oil vapours control some common postharvest pathogens. Australian Journal of Experimental Agriculture, 47, 103-109. http://dx.doi.org/10.1071/EA05236

Udomsilp, J., Piyo, A., Khang-Khun, P., \& Thobunluepop, P. (2009). Antifungal properties of essential oils from Thai medicinal plants against rice pathogenic fungi. Asian Journal of Food and Agro-Industry, Special Issue, S24-S30.

Velazhahan, R., Vijayanandraj, S., Vijayasamundeeswari, A., Parandidharan, V., Samiyappan, R., Iwamoto, T., ... Muthukrishnan, S. (2010). Detoxification of aflatoxin by seed extracts of the medicinal plants, Trachyspermum ammi (L.) Sprangue ex Turrill-structural analysis and biological toxicity of degradation product of aflatoxin $\mathrm{G}_{2}$. Food Control, 21, 719-725. http://dx.doi.org/10.1016/j.foodcont.2009.10.014 
Vermaak, I., Kamatou, G. P. P., Komane-Mofokeng, B., Viljoen, A. M., \& Beckett, K. (2011). African seed oils of commercial importance-Cosmetic applications. South African Journal of Botany, 77, 920-933. http://dx.doi.org/10.1016/j.sajb.2011.07.003

Wagacha, J. M., \& Muthomi, J. W. (2008). Mycotoxin problem in Africa: Current status, implications to food safety and health and possible management strategies. International Journal of Food Microbiology, 124, 1-12. http://dx.doi.org/10.1016/j.ijfoodmicro.2008.01.008

Wickens, G. E., \& Lowe, P. (2008). The Baobabs: Pachycauls of Africa, Madagascar and Australia. London: Springer. http://dx.doi.org/10.1007/978-1-4020-6431-9 